\title{
KẾT QUẢ ĐIỀU TRI CHẤN THƯƠNG SỌ NÃO NHẸ TẠI BỆNH VIỆN ĐA KHOA TİNH THÁI BÌNH
}

\section{TÓM TẮT}

Mục tiêu: Nhận xét đặc điểm lâm sàng, tổn thương trên chụp cắt lớp vi tính và kết quả điêu trị chấn thương sọ não nhẹ. Phương pháp: Mô tả cắt ngang 501 bênh nhân chấn thương so não nhe (GCS từ 13-15 điểm) điều trị tại khoa Phẩu thuật Thần kinhCột sống Bệnh viên Đa khoa tỉnh Thái Bình trong khoảng thời gian từ tháng 2 đến tháng 9 năm 2020. Kết quả: 501 bênh nhân gồm 344 nam $(68,7 \%), 157$ nữ (31,3\%). Tuổi trung bình: 44,96 $\pm 21,92$ tuổi; Tuổi nhỏ nhất: 2 tuổi; Tuối cao nhất: 96 ; Nhóm tuối (1959) chiếm (57,6\%); nhóm tuổi (60-96) chiếm $(29,5 \%)$. Nguyên nhân tai nạn giao thông chiếm tỉ lệ cao nhất $(60,9 \%)$, tai nạn sinh hoạt $(29,5 \%)$, tai nạn lao động $(5,0 \%)$. Lâm sàng triệu chứng đau đầu chiếm $(88,6 \%)$; vết thương rách da đầu $(38,9 \%)$; tụ máu dưới da đâuu (24,8\%); nôn (20,0\%). 64,3\% bệnh nhân chấn thương so não nhe chup cắt lớp vi tính có tổn thương nội sọ trong đó có 1 tổn thương chiếm $45,3 \%$, có 2 tổn thương phối hợp chiếm $(15,0 \%)$, có từ 3 tổn thương phối hợp (4,0\%). Đa số bệnh nhân điêu trị nội khoa, chỉ có 42 bệnh nhân $(8,4 \%)$ trong quá trình theo dối và điêuu trị xấu đi có chỉ định phẫu thuật. Kết quả ra viện đa số tốt $(97,6 \%)$, tuy nhiên vẫn có $(0,4 \%)$ bệnh nhân sống thực vật và tử vong là $(0,2 \%)$. Kết luận: Chấn thương sọ não nhẹ có tî lệ máu tụ nội sọ $(64,3 \%)$, đa số điều trị nội khoa cho kết quả tổt tuy nhiên diến biến phức tạp, vẫn có bệnh nhân diến biến nặng để lại di chứng nặng và tử vong.

Tư khóa: Chấn thưởing sọ não nhẹ, chấn thương sọ não nguy cơ thấp, chấn thương sọ nã̃o.

\section{SUMMARY \\ OUTCOMES OF MILD TRAUMATIC BRAIN INJURY TREATMENT AT THAI BINH GENERAL HOSPITAL}

Objectives: To assess clinical characteristics, lesions on CT scan images and outcomes of mild traumatic brain injury treatment. Methods: A descriptive cross-sectional study was conducted in 501 patients with mild traumatic brain injury (GCS from 13-15 points) treated at Neuro-Spinal Surgery Department of Thai Binh General Hospital in the period from February to May, September 2020. Results: 501 patients, including 344 males (68.7\%), 157 females (31.3\%). Median age: $44.96 \pm 21.92$ years old; the youngest: 2 years old; the oldest: 96 ; (19-59) age group accounted for (57.6\%); (60-96) age group made up $(29.5 \%)$. Traffic accidents were in

*Trường Đại học Y Dược Thái Bình

Chiu trách nhiếm chính: Vũ Minh Hải

Email: vuminhhai777@gmail.com

Ngày nhận bài: 13.5 .2021

Ngày phản biện khoa học: 6.7.2021

Ngày duyệt bài: 16.7.2021
Vũ Minh Hải*

the highest rate (60.9\%), domestic accidents (29.5\%), occupational accidents $(5.0 \%)$. Clinical symptoms: headache was comprised of (88.6\%); scalp wounds $(38.9 \%)$; scalp hematomas $(24.8 \%)$; vomiting $(20.0 \%) .64 .3 \%$ of patients with mild traumatic brain injuries who were scanned with CT scan had intracranial lesions, of which 1 lesion accounted for $45.3 \%$, 2 combined lesions formed $(15.0 \%)$, from 3 combined lesions and over contributed (4.0\%). The majority of patients were treated non-operatively, only 42 patients $(8.4 \%)$ during follow-up and treatment worsened and had indications for surgery. Most of the hospital discharge results were good, accounting for $(97.6 \%)$, but there were still $(0.4 \%)$ having vegetative state and death $(0.2 \%)$. Conclusion: Mild traumatic brain injuries with intracranial hematomas amounted to $(64.3 \%)$, most of the medication treatment gave good outcomes, however, the progress was complicated, there were still patients who developed severe conditions which left severe sequelae and deaths.

Keywords: Mild traumatic brain injuries, Traumatic brain injuries, Road traffic accidents

\section{I. ĐĂT VẤN ĐỀ}

Chấn thương sọ não nhẹ là chấn thương sọ não mà bệnh nhẩn còn tương đối tỉnh và có thang điểm đánh giá tri giác (GCS) từ 13-15 điểm. Chấn thương so não nhẹ chiếm đa số (80\%) trong tổng số bệnh nhân chấn thương sọ não nhập viện. Mặc dù sau khi bị chấn thương bệnh nhân còn tỉnh nhưng luôn có khả năng xuất hiện máu tụ nội sọ, chèn ép não và đe dọa tính mang bênh nhẩn. Khi khám và điều trị cho nhóm bệnh nhân này, chúng ta phải hết sức lưu ý để tránh sai lầm vì chính người bệnh đôi khi cũng chủ quan, gia đình bệnh nhân ít quan tâm "vì cho rằng bệnh nhẹ" và thầy thuốc có thể cũng chưa đánh giá hết diễn biến phức tạp và mức độ nguy hiểm. Chúng tôi mô tả đặc điểm tổn thương, kết quả điều trị nhóm bệnh nhân này nhằm mục đích nâng cao hiệu quả điều trị chấn thương sọ não nhẹ tại Bệnh viện Đa khoa tỉnh Thái Bình.

\section{II. ĐỐI TƯƠNG VÀ PHƯƠNG PHÁP NGHIÊN CỨU}

2.1. Địa bàn nghiên cứu. Bệnh viện $Đ a$ khoa tỉnh Thái Bình

2.2. Đối tượng nghiên cứu. 501 bệnh nhân chấn thương sọ não nhe điều trị tại khoa Phẫu thuật Thần kinh-Cột sống Bệnh viện Đa khoa tỉnh Thái Bình trong khoảng thời gian từ tháng 2 đến tháng 9 năm 2020.

\subsection{Phương pháp nghiên cứu}


Mô tả cắt ngang: lâm sàng, chụp cắt lớp vi tính và kết quả điều trị

\section{KẾT QUẢ NGHIÊN CỨU}

Bảng 3.1 Phân bô theo nhóm tuổi, giới

\begin{tabular}{|c|c|c|c|c|}
\hline \multirow{2}{*}{ Gióón tuới } & \multicolumn{2}{|c|}{ Nam } & \multicolumn{2}{c|}{ Nữ } \\
\cline { 2 - 5 } Nom & $\mathbf{n}$ & $\mathbf{\%}$ & $\mathbf{n}$ & $\mathbf{\%}$ \\
\hline$\leq 18$ & 49 & 75,4 & 16 & 24,6 \\
\hline $19-29$ & 62 & 79,5 & 16 & 20,5 \\
\hline $30-39$ & 40 & 66,7 & 20 & 33,3 \\
\hline $40-49$ & 50 & 65,8 & 26 & 34,2 \\
\hline $50-59$ & 51 & 68,0 & 24 & 32,0 \\
\hline $60-69$ & 53 & 70,7 & 22 & 29,3 \\
\hline $70-79$ & 27 & 61,4 & 17 & 38,6 \\
\hline$\geq 80$ & 12 & 42,9 & 16 & 57,1 \\
\hline Tống & $\mathbf{3 4 4}$ & $\mathbf{6 8 , 7}$ & $\mathbf{1 5 7}$ & $\mathbf{3 1 , 3}$ \\
\hline
\end{tabular}

Nhân xét: 501 bênh nhân gồm 344 nam $(68,7 \%), 157$ nữ, chiếm $(31,3 \%)$. Tuổi trung bình: 44,96 $\pm 21,92$; Tuổi nhỏ nhất: 2 Tuổi cao nhất: 96; Nhóm tuô̂i (19-59) có 289 bênh nhân (57,6\%); nhóm tuổi (60-96) có 148 bệnh nhân $(29,5 \%)$.

Bảng 3.2 Nguyên nhân chấn thương

\begin{tabular}{|c|c|c|c|}
\hline Nguyên nhân & $\mathbf{n}$ & $\begin{array}{c}\text { Tỷ lệ } \\
\mathbf{\%}\end{array}$ & $\begin{array}{c}\text { Tống } \\
\mathbf{\%}\end{array}$ \\
\hline Tai nạn giao thông & 305 & 60,9 & \multirow{2}{*}{95,4} \\
\cline { 1 - 3 } Tai nạn lao động & 25 & 5,0 & \multirow{2}{*}{95,4} \\
\hline Tai nạn sinh hoạt & 148 & 29,5 & \\
\hline Bạo lực & 23 & 4,6 & 4,6 \\
\hline Tống & $\mathbf{5 0 1}$ & $\mathbf{1 0 0}$ & $\mathbf{1 0 0}$ \\
\hline
\end{tabular}

Nhân xét: Tai nạn giao thông chiếm tỉ lệ cao nhất $(60,9 \%)$, tai nạn sinh hoạt $(29,5 \%)$, tai nạn lao động (5,0\%); Bạo lực chiếm (4,6\%).

Bảng 3.3 Các triệu chứng lâm sàng

\begin{tabular}{|c|c|c|}
\hline Triệu chứng & n & Tỷ lệ \% \\
\hline Đauu đâu & 444 & 88,6 \\
\hline Nôn & 100 & 20,0 \\
\hline Liệt nứa người & 12 & 2,4 \\
\hline Co giật, động kinh & 3 & 0,6 \\
\hline Chảy máu mũi & 27 & 5,4 \\
\hline Chảy máu tai & 26 & 5,2 \\
\hline Bầm tím quanh mắt & 53 & 10,6 \\
\hline Rò dịch não tủy qua mũi, họng & 2 & 0,4 \\
\hline Tụ máu, sưng nề dưới da đâu & 124 & 24,8 \\
\hline Vết thương vừng đâu & 195 & 38,9 \\
\hline Khoảng tỉnh & 23 & 4,6 \\
\hline
\end{tabular}

Nhân xét: Triêu chứng đau đầu chiếm (88,6\%); vết thương rách da đầu $(38,9 \%)$; tụ máu dưới da đâu $(24,8 \%)$; nôn $(20,0 \%)$. Theo dõi có 23 bệnh nhân $(4,6 \%)$ có khoảng tỉnh.

Bảng 3.4 Tổn thương trên chụp cắt lớp vi tính so não

\begin{tabular}{|c|c|c|}
\hline Tốn thương sọ não & $\mathbf{n}$ & Tỷ lệ \%o \\
\hline Vỡ xương sọ & 62 & 12,4 \\
\hline Máu tụ ngoài màng cứng & 74 & 14,8 \\
\hline
\end{tabular}

\begin{tabular}{|c|c|c|c|}
\hline \multicolumn{2}{|c|}{ Máu tụ dưới màng cúng cấp tính } & 134 & 26,7 \\
\hline \multicolumn{2}{|c|}{ Máu tụ trong não } & 34 & 6,8 \\
\hline Chảy máu khoang dưới nhện & 137 & 27,3 \\
\hline \multicolumn{2}{|c|}{ Không thấy tốn thương } & 179 & $\mathbf{3 5 , 7}$ \\
\hline \multirow{2}{*}{$\begin{array}{c}\text { Có tổn } \\
\text { thương } \\
(\mathbf{6 4 , 3 \% )}\end{array}$} & $\begin{array}{c}1 \text { tốn thương } \\
\text { đơn thuần }\end{array}$ & 227 & 45,3 \\
\cline { 2 - 4 } & $\begin{array}{c}2 \text { tổn thương } \\
\text { phối hợp }\end{array}$ & 75 & 15,0 \\
\cline { 2 - 4 } & $\begin{array}{c}\geq 3 \text { tốn thương } \\
\text { phối hợp }\end{array}$ & 20 & 4,0 \\
\hline
\end{tabular}

Nhận xét: $64,3 \%$ bệnh nhân chấn thương sọ não nhe chụp cắt lớp vi tính có tổn thương nội so trong đó có 1 tổn thương chiếm $45,3 \%$, có 2 tổn thương phối hợp chiếm $(15,0 \%)$, có từ 3 tổn thương phối hợp (4,0\%).

Bảng 3.5 Các tổn thương phôi hợp

\begin{tabular}{|c|c|c|}
\hline Tốn thương phối hợp & $\mathbf{n}$ & Tỷ lệ \% \\
\hline Vết thương rách da & 186 & 37,1 \\
\hline Vễt thương bàn tay & 17 & 3,4 \\
\hline Chấn thương hàm mặt & 117 & 23,4 \\
\hline Chấn thương cột sống cố & 16 & 3,2 \\
\hline $\begin{array}{c}\text { Chấn thương cột sống } \\
\text { ngực thắt lưng }\end{array}$ & 5 & 1,0 \\
\hline Chấn thương ngực & 14 & 2,8 \\
\hline Chấn thương bụng & 2 & 0,4 \\
\hline Gãy xương chi & 55 & 11,0 \\
\hline Bỏng & 1 & 0,2 \\
\hline
\end{tabular}

Nhân xét: Vết thương rách da chiếm $(37,1 \%)$; chấn thương hàm mặt $(23,4 \%)$; gãy xương chi chiếm $(11,0 \%)$

Bảng 3.6 Thái độ xừ trí

\begin{tabular}{|c|c|c|}
\hline & $\mathbf{n}$ & Tỷ lệ \% \\
\hline Hồi sức & 1 & 0,2 \\
\hline Nội khoa & 458 & 91,4 \\
\hline Phẩu thuật & 42 & 8,4 \\
\hline Tống số & $\mathbf{5 0 1}$ & $\mathbf{1 0 0}$ \\
\hline
\end{tabular}
khoa, chỉ có 42 bênh nûân $(8,4 \%)$ trong quá trình theo dõi và điểu trị xấu đi có chỉ định phẫu thuật.

Bảng 3.7 Các phương pháp phẫu thuật

\begin{tabular}{|c|c|c|}
\hline Phương pháp & $\mathbf{n = 4 2}$ & Tỷ lệ \% \\
\hline $\begin{array}{c}\text { Phẩu thuật máu tụ ngoài } \\
\text { màng cứng }\end{array}$ & 9 & 21,4 \\
\hline $\begin{array}{c}\text { Phẩu thuất máu tụ dưới } \\
\text { màng cứng cấp tính }\end{array}$ & 8 & 19,0 \\
\hline $\begin{array}{c}\text { Phâu thuật máu tụ nhu mô } \\
\text { não }\end{array}$ & 4 & 9,5 \\
\hline $\begin{array}{c}\text { Phâu thuất máu tụ dưới } \\
\text { màng cứng bán cấp }\end{array}$ & 15 & 35,7 \\
\hline Phâuu thuật giải tỏa não & 4 & 9,5 \\
\hline Vết thương sọ não & 2 & 4,7 \\
\hline
\end{tabular}

Nhận xét: 42 bệnh nhân trong tống số 501 bệnh nhân chấn thương sọ não nhẹ có diễn biến lâm sàng xâu đi, tổn thướng máu tụ chèn ép đã 
được phẫu thuật (8,4\%). Trong 42 bệnh nhân thì máu tụ ngoài màng cứng chiếm $21,4 \%$; máu tụ dưới màng cứng bán cấp 35,7\%.

\section{Bảng 3.8 Tình trạng ra viện}

\begin{tabular}{|c|c|c|}
\hline Kết quả điêu trị chung & $\mathbf{n}$ & Tỷ lệ \% \\
\hline Tốt & 489 & 97,6 \\
\hline Khá & 7 & 1,4 \\
\hline Trung bình & 2 & 0,4 \\
\hline Kém & 2 & 0,4 \\
\hline Tứ vong & 1 & 0,2 \\
\hline Tống & $\mathbf{5 0 1}$ & $\mathbf{1 0 0}$ \\
\hline
\end{tabular}

Nhận xét: Kết quả ra viện đa số tốt, chiếm tỉ lệ $(97,6 \%)$, tuy nhiên vẫn có $(0,4 \%)$ bệnh nhân sống thực vật và tỉ lệ tử vong là $(0,2 \%)$.

\section{BÀN LUÂN}

4.1. Tuổi, giới. Nghiên cứu này ghi nhận 501 bệnh nhân chấn thương sọ não nhẹ (GCS 13-15 điểm) điều trị tại Khoa phẫu thuật Thần kinh-Cột sống Bệnh viện Đa khoa tỉnh Thái Bình trong khoảng thời gian từ tháng 2 đến tháng 9 năm 2020. Ghi nhận 344 nam (68,7\%), 157 nữ, chiếm (31,3\%). Tuổi trung bình: 44,96 $\pm 21,92$; Tuổi nhỏ nhất: 2 Tuổi cao nhất: 96 ; Nhóm tuổi (19-59) có 289 bệnh nhân ( 57,6\%); nhóm tuổi (60-96) có 148 bệnh nhân (29,5\%). Theo Đồng Văn Hệ và cộng sự (2010), nghiên cứu 232 bệnh nhân chấn thương sọ não nguy cơ thấp (điểm GCS từ 13-15) tại Bệnh viện Hữu Nghị Việt Đức thì nam giới chiếm $(79,3 \%)$, nữ chiếm (20,7\%)[1]. Theo Phạm Ty. (2010), báo cáo 1632 bệnh nhân chấn thương sọ não nhẹ tại Bệnh viện Đa khoa tỉnh Bình Định, thì nam chiếm $(62,5 \%)$, nữ $(37,5 \%)$; nhóm tuổi từ (16-59) chiếm $(84,9 \%)$ [2]. Chúng tôi cùng nhận xét với 2 tác giả là đa số chấn thương sọ não gặp ở nam giới và độ tuổi lao động.

4.2. Nguyên nhân. Nghiên cứu này thấy nguyên nhân tai nạn giao thông chiếm tỉ lệ cao nhất $(60,9 \%)$, tai nạn sinh hoạt $(29,5 \%)$, tai nạn lao động $(5,0 \%)$; Bạo lực chiếm (4,6\%). Báo cáo của chúng tôi thì nguyên nhân tai nạn giao thông thấp hơn của Phạm Ty (2010), nguyên nhân tai nạn giao thông chiếm $(78,9 \%)$, tai nạn sinh hoạt $(6,5 \%)$ nhưng nguyên nhân tai nạn sinh hoạt chủ yếu do ngã của chúng tôi cao hơn Phạm Ty. [2].

4.3. Lâm sàng và chẩn đoán hình ảnh. Lâm sàng triệu chứng đau đầu chiếm $(88,6 \%)$; vết thương rách da đầu $(38,9 \%)$; tụ máu dưới da đầu $(24,8 \%)$; nôn $(20,0 \%)$, bầm tím quanh mắt $(10,6 \%)$. Theo dõi có 23 bệnh nhân $(4,6 \%)$ có khoảng tỉnh trong quá tỉnh điều trị. Đồng Văn Hệ, (2010) cho biết triệu chứng đau đầu chiếm $(65,3 \%)$, nôn, buồn nôn $(78,2 \%)$ [2].
Hình ảnh chụp cắt lớp vi tính: 64,3\% bệnh nhân chấn thương sọ não nhẹ có tổn thượng máu tụ, trong đó có 1 tổn thương chiếm 45,3\%, có 2 tổn thương phối hợp chiếm $(15,0 \%)$, có từ 3 tổn thương phối hợp $(4,0 \%)$. Vỡ xương sọ $(12,4 \%)$; Máu tụ ngoài màng cứng $(14,8 \%)$; máu tụ dưới màng cứng cấp tính $(26,7 \%)$; máu tụ trong não $(6,8 \%)$; chảy máu khoang dưới nhện $(27,3 \%)$. Đồng Văn Hệ (2010) cho biết chẩn thương sọ não nguy cơ thấp, chụp cắt lớp vi tính có $(78,9 \%)$ máu tụ nội sọ. Trong đó chảy máu khoang dưới nhện $(45,7 \%)$, dập não chảy máu $(27,6 \%)$, tụ máu ngoài màng cứng $(18,5 \%)$, máu tụ dưới màng cứng $(14,2 \%)$, máu tụ trong não $(7,8 \%)$, võ xương so $(12,5 \%)$. Theo Amir Saied Seddighi và cộng sự (2013), đánh giá 203 bệnh nhân chấn thương sọ não nhẹ. Chụp cắt lớp vi tính não được thực hiện ở tất cả các bệnh nhân và theo dõi trong 6-48 giờ. Kết quả trong số những bệnh nhân này, $2,5 \%$ bị chấn thương sọ não và vị trí thường xảy ra xung huyết nhất là thùy trán; $94 \%$ bệnh nhân không có máu tụ trong lần chụp ban đầu, trong khi 3\% có máu tụ dưới màng cứng, $1,5 \%$ có máu tụ dưới màng cứng, $1 \%$ có xuất huyết dưới nhện, $0,5 \%$ xuất huyết trong não và $0,5 \%$ xuất huyết ngoài màng cứng [5]. Theo Đồng Văn Hệ sở dĩ tỉ lệ tổn thương máu tụ nội sọ được phát hiện $(78,9 \%)$, của chúng tôi là $(64,3 \%)$ cao hơn báo cáo của các tác giả nước ngoài có thể do chỉ định chụp cắt lớp vi tính khá hẹp và chặt chẽ. Những bệnh nhân chấn thương sọ não nguy cơ thấp, ít có dấu hiệu lâm sàng chưa được chụp cắt lớp vi tính hoặc không đưa vào nghiên cứu. Còn ở các nước phát triển thì chỉ định chụp cắt lớp vi tính cho bệnh nhân đã thành thường quy.

4.4. Kết quả điêuu trị. Đa số bệnh nhân của chúng tôi điêuu trị nội khoa $(91,6 \%)$, chỉ có 42 bệnh nhân $(8,4 \%)$ trong quá trình theo dõi lâm sàng bệnh nhân tri giác giảm 2 điểm, chụp cắt lớp vi tính thấy máu tụ to lên $(30 \mathrm{ml}$ với máu tụ ngoài màng cứng, dày trên $10 \mathrm{~mm}$ với máu tụ dưới màng cứng và đường giữa di lệch trên $5 \mathrm{~mm})$. Kết quả ra viện đa số tốt $(97,6 \%)$, tuy nhiên vẫn có $(0,4 \%)$ bệnh nhân sống thực vật và tỉ lệ tử vong là $(0,2 \%)$. Kết quả của Đồng Văn Hệ (2010), điều trị nội khoa chiếm (92,7\%), kết quả chung đa số hồi phục tốt, tỉ lệ tử vong là $(1,3 \%)$. Timothy $E$ Sweeney và cộng sự (2015), nghiên cứu 50.496 bệnh nhân chấn thương sọ não nhè, với tỷ lệ can thiệp phẫu thuật thần kinh là $8,8 \%$. Tác giả cho biết tỉ lệ can thiệp phẫu thuật thần kinh thay đổi rõ rệt tùy theo loại tổn thương. Bệnh nhân bị tràn dịch não hoặc xuất 
huyết dưới nhện ít cân can thiệp phẫu thuật hơn [3]. Pierre Borczuk và cộng sự (2018), báo cáo 1079 bệnh nhân chấn thương sọ não nhê. Trong số này, 92,4\% được điêuu trị không phẫu thuật và $35,8 \%$ được xuất viện trong vòng 24 giờ sau khi đến điều trị tại đơn vị cấp cứu [4].

\section{KẾT LUÂ̂N}

Chấn thương sọ não nhẹ có tỉ lệ máu tụ nội sọ (64,3\%), đa số điểu trị nội khoa cho kết quả tốt, tuy nhiên diễn biến phức tạp, vẫn có bệnh nhân diên biến nặng để lại di chứng nặng và tử vong.

\section{TÀI LIÊU THAM KHẢO}

1. Đồng Văn Hệ, Kiêuu Đình Hùng (2010), Chẩn đoán và điêuu trị chấn thương sọ não nguy có thấp,
Y học Việt Nam tháng 7- số 1/2010.

2. Pham Ty (2010), Điều tri chấn thương so não nhẹ, Y học Việt Nam tháng 6-số 1/2010.

3. Timothy E Sweeney, và cộng sự (2015), Prediction of neurosurgical intervention after mild traumatic brain injury using the national trauma data bank. World J Emerg Surg. 2015 Jun 6;10:23. doi: 10.1186/s13017-015-0017-6.

4. Pierre Borczuk và cộng sự (2018), Rapid Discharge After Interfacility Transfer for Mild Traumatic Intracranial Hemorrhage: Frequency and Associated Factors. West J Emerg Med. 2019 Mar;20(2):307-315

5. Amir Saied Seddighi và công sự (2013) Factors predicting early deterioration in mild brain trauma: a prospective study. Brain Inj 2013;27(1314):1666-70. doi: 10.3109/02699052.2013.830333.

\title{
ĐÁNH GIÁ MỨC Độ LO ÂU CỦA CÁN Bộ Y TẾ TUYẾN ĐẦU CHỐNG DICH TRONG THỜI GIAN DICH COVID-19 DIỂN BIẾN PHỨC TẠP TẠI ĐÀ NẲNG
}

\author{
Ngô Thị Kim Yến ${ }^{1}$, Trần Thị Hoài Vi ${ }^{1}$, Trần Thanh Thủy ${ }^{1}$, \\ Nguyễn Tiên Hồng ${ }^{1}$, Phạm Thị Kim Chi ${ }^{1}$, Trương Văn Trình ${ }^{1}$,
} Võ Thu Tùng ${ }^{1}$, Nguyễn Ngọc Thanh ${ }^{1}$, Võ Văn Thắng ${ }^{2}$

\section{TÓM TẮT}

Mục tiêu nghiên cứu: Đánh giá mức độ lo âu của các cán bộ $y$ tế tuyến đầu chống dich và mô tả các yếu tố liên quan đến mức độ lo âu của các cán bộ y tế trong thời điểm dịch COVID-19 diễn biến phức tạp tại các cơ sở y tế tuyến đầu chống dịch. Đối tượng và phương pháp nghiên cứu: Cán bộ y tế tại các cơ sở y tế tuyến đầu phòng, chống dịch COVID-19, cụ thể gồm 04 đơn vị: Bệnh viện Đà Nẵng, Bệnh viện Phổi, Trung tâm Y tế huyện Hì̀a Vang (Bệnh viện dã chiến Hoà Vang), Trung tâm Kiểm soát bệnh tật. Tiêu chuẩn chọn đối tượng nghiên cứu: Cán bộ y tế tai các đơn vị tuyến đầu chống dịch COVID-19 tại thời điểm làn sóng dịch thứ 2 tại thành phố Đà Nẵng; Trên 18 tuổi; Không có rối loạn năng lực nhận thức và hành vi; Đồng ý tham gia nghiên cứu. Tiêu chuẩn loại trừ đối tượng nghiên cứu. Không đáp ứng tiêu chuẩn chọn đổi tượng nghiên cứu. Phương pháp nghiên cứu: Nghiên cứu mô tả cắt ngang có phân tích được thực hiện từ tháng 01/2021 đến tháng 05/2021 trển 602 cán bộ y tế đang công tác tại các cơ sở y tế tuyến đầu chống dịch bằng hình thức phỏng vấn trực tiếp đối tượng đích. Bộ cầu hỏi được thiết kế sẵn sử dụng các cẩu hỏi nhiều lựa chọn và sử dụng thang đo DASS21 (lấy ra 07 câu đánh giá về mức độ lo âu).

${ }^{1}$ Sở Y tế thành phố Đà Nẵng

2Viện Nghiên cứu sức khóe cộng động - Trường Đại hoc Y Dướ Huê

Chịu trách nhiệm chính: Trần Thị Hoài Vi

Email: vitth@danang.gov.vn

Ngày nhân bài: 17.5.2021

Ngày phản biên khoa hoc: 8.7.2021

Ngày duyệt bài: 19.7.2021

\begin{tabular}{|c|c|}
\hline Mức độ lo âu & Điếm Lo âu \\
\hline Bình thường & $0-7$ \\
\hline Nhẹ & $8-9$ \\
\hline Vừa & $10-14$ \\
\hline Nặng & $15-19$ \\
\hline Rất nặng & $\geq 20$ \\
\hline
\end{tabular}

Thang đo DASS21 đã được Viên Sức khoẻ tâm thân Quốc gia biên dịch, thử nghiệm trên một số đối tượng nghề nghiệp khác nhau. Thang đo DASS21 đã được nhiều nghiển cứu đánh giá về tính giá trị, độ tin cậy và khẳng đinh có thể áp dụng tai Viêt Nam, không có sư khác biệt về mặt văn hoá. Kểt quả: Trong số 602 đổi tượng tham gia khảo sát, tỷ lệ có biểu hiện rối loạn lo âu ở mức rất cao (70,1\%). Tỷ lệ đối tượng rối loạn lo âu nhe, vừa, năng và rất nặng lần lướt là $6,6 \%, 18,8 \%$ và $44,6 \%$ \% tổng số đối tượng. Tình trạng lo âu hay xảy ra bao gồm: Cảm thây bị khô miệng, hay lo lắng về các tình huống có thể khiến bản thân bẽ mặt, hay bị ra mồ hôi trộm. Có 03 yếu tố dân số và công việc liên quan đến biểu hiện rối loạn lo âu của đối tượng nghiên cứu, trong đó các yếu tố về dân số bao gồm: cơ sở tuyến đâu chống dịch (Biểu hiện lo âu ở Bệnh viện Đà Nẵng cao hơn so với những đổi tượng công tác tại các đơn vị khác $(\mathrm{OR}=3,382 ; 95 \% \mathrm{CI}$ : 1,832-6,243; $p<0,05)$; các yếu tố khác từ công việc liên quan đến biểu hiện lo âu gồm: có tiếp xúc với bệnh nhân COVID$19(\mathrm{OR}=0,361 ; 95 \% \mathrm{CI}: 0,547-1,238 ; \mathrm{p}<0,05)$, tổng điểm áp lực từ nhóm 07 yếu tố áp lực liên quan đến công việc ở mức cao (OR=1,246; 95\%CI: 1,159-1,342; $\mathrm{p}<0,05)$. Kết Iuân: Nghiên cứu chỉ ra trang thái lo âu của các cán bộ tuyến đâu chống dịch bị tắc động nhiêu bởi dich COVID-19 trong thời điểm Đà Nẵng đước xem là tâm dịch COVID-19 của cả nước. Cần có nhiều biện pháp can thiệp để bảo vệ đội ngũ cán bộ y tế trong thời gian đến. 